\title{
1- O nordeste nas páginas dos livros didáticos
}

\author{
Rosiane Rocha Oliveira Santos ${ }^{1}$ \\ José Moacir dos Santos ${ }^{2}$
}

\section{Resumo}

A partir de uma pesquisa documental de abordagem qualitativa, que avaliou 04 livros didáticos de Geografia utilizados em várias escolas públicas do país no período dos anos 2000 a 2011 o presente trabalho avalia a representação do Nordeste Brasileiro nos livros didáticos. Tal análise repercute as formas de representação dos aspectos antropossociais do Nordeste e os estereótipos e estigmas sociais que historicamente se atribuíram às nossas gentes, como falácias que funcionam como sustentáculos de uma lógica de dominação erigida por uma epistemologia que impossibilita o reconhecimento da coexistência de diferentes formas de ser no mundo.

Palavras-chave: Semiárido Nordestino. Educação. Nordeste. Livros Didáticos. Contextualização.

\begin{abstract}
From a documentary research of qualitative approach, which evaluated 04 textbooks of Geography used in several public schools of the country in the period from 2000 to 2011 the present work evaluates the representation of the Brazilian Northeast in textbooks. Such an analysis affects the forms of representation of the anthropossocial aspects of the Northeast and the stereotypes and social stigmas that historically have been attributed to our people, such as fallacies that function as pillars of a logic of domination erected by an epistemology that makes it impossible to recognize the coexistence of different forms of being in the world.
\end{abstract}

Keywords: Semi-arid Northeastern. Education. Northeast. Didatic books. Contextualization.

\section{Resumen}

A partir de una investigación documental de abordaje cualitativo, que evaluó 04 libros didácticos de Geografía utilizados en varias escuelas públicas del país en el período de los años 2000 a 2011, el presente trabajo evalúa la representación del Nordeste de Brasil en los libros didácticos. Este análisis repercute las formas de representación de los aspectos antroposociales del Nordeste y los estereotipos y estigmas sociales que históricamente se atribuyeron a nuestras gentes como falacias que funcionan como

\footnotetext{
${ }^{1}$ Pedagoga e Mestra em Educação, Cultura e Territórios Semiáridos pela Universidade do Estado da Bahia (UNEB). Atualmente é Prof ${ }^{a}$. Pedagoga na Faculdade de Ciências Aplicadas e Sociais de Petrolina (FACAPE).

2 Pedagogo pela Universidade do Estado da Bahia (UNEB) e Especialista em Extensão Rural e Metodologias Participativas pela Universidade Federal do Vale do São Francisco (UNIVASF). Atualmente é Presidente do Conselho Estadual de Segurança Alimentar (CONSEA/BA) e Coordenador do Eixo de Produção do Instituto Regional da Pequena Agropecuária Apropriada (IRPAA).
} 
sostenimientos de una lógica de dominación erigida por una epistemología que imposibilita el reconocimiento de la coexistencia de diferentes formas de ser en el mundo.

Palabras clave: Semiárido Nordestino. Educación. Noreste. Libros Didácticos. Contextualización.

\section{Introdução}

No toque do tambor, tamburetes e pandeiros

Afro-nordestinos, índios brasileiros

Em nossos braços a força criadora Somos muito mais que coordenação motora

Indígenas, sertanejos, ribeirinhos João de barro que nunca deixa o ninho

Mulheres fortes, homens valentes Contaram nossa história, Mas não por nossa gente

É pra quem pensa ser melhor, nossa risada Na linha de seu Lunga, língua afiada Aqui o pensar é rápido pick João grilo João Candido na proa almirante destemido

É mais que roupa de couro e chupar rapadura É mais que um coca, cabelo crespo e pele escura É alma que já nasce forte tipo luz de lampião Samurai do agreste sabre, catana, facão

Raízes na cabeça dread, tranças Alfaia, índio, flecha, lança Memórias, contos, rezas, danças Promessas, velas, lágrimas, esperança

Sem esquecer a nossa hospitalidade Seja no campo, aldeias ou cidades

Portas abertas, e coração bondoso Nordestino sim e Preto, Índio orgulhoso

(P1 RAPPERS, 2017)

Se pesquisarmos rapidamente na internet a palavra Nordeste, encontraremos dois conjuntos de imagens. Um deles propaga as inúmeras praias e áreas turísticas da faixa litorânea dessa região. O outro anuncia imagens caóticas com gente magra e doente, gado morto, chão rachado, casas de barro, estampando as primeiras linhas das ferramentas de busca disponíveis na rede. Nos outros meios de comunicação e demais tecnologias, não é muito diferente, uma vez que tanto os jornais, como revistas, sites ou livros dispõem de fontes semelhantes de informação. Nesse sentido, o presente trabalho versa sobre como essas representações são disseminadas também através do Livro 
Didático (LD), por ser esse uma das tecnologias que permeiam o ambiente escolar e, consequentemente, forma opiniões em todo o país.

A partir de uma pesquisa de abordagem qualitativa, que avaliou LD distribuídos pelo Ministério da Educação, utilizados em várias escolas públicas do país, no período dos anos 2002 a 2013 (considerando que cada livro tem um período de utilização trianual), foram selecionados de uma escola pública de Juazeiro/BA quatro livros da disciplina de Geografia do sétimo ano do ensino fundamental que tinham sido usados durante esses 12 (doze) anos. A escolha da escola para a seleção dos livros se deu por ser a maior escola pública municipal da referida cidade, que possui biblioteca com grande acervo dos livros didáticos utilizados. Entretanto, é interessante ressaltar que os livros utilizados nessa escola são os mesmos utilizados em toda a rede desse município, uma vez que são adotados pela rede municipal como um todo. Portanto, tal seleção dos materiais ocorreu pelo fato de serem exatamente os livros distribuídos pelo Ministério da Educação às escolas da rede municipal de Juazeiro/BA para serem trabalhados nas turmas de sétimo ano, nas quais são trabalhadas as regiões brasileiras e suas características como clima, população, economia, cultura, etc.

Trata-se de uma pesquisa documental, que, segundo Gil (2012), apresenta inúmeras vantagens como o baixo custo, a fonte estável de dados, o não prejuízo devido a circunstâncias que envolvem o contato, no caso de se fazer uma entrevista, como por exemplo, coleta de dados em ambientes ruidosos ou respostas de questionários que podem sofrer interferências devido ao contexto do sujeito que responde. No que diz respeito à subjetividade do trabalho, é importante destacar a cautela e idoneidade com que foram discutidos e considerados os dados obtidos nesta pesquisa, através da elaboração de um mapa conceitual para um trabalho qualitativo com vistas a contribuir com a prática desenvolvida com o livro didático e com os novos olhares que devem ser lançados sobre os mesmos no seu processo de produção, escolha e uso. Nesse levantamento de dados, foram considerados os anos adotados, nomes de autores, números de páginas e ordem de apresentação das regiões brasileiras. Para referenciar os livros, no decorrer do trabalho, usou-se um código elaborado a partir da análise dos livros.

Para facilitar a identificação dos livros no decorrer do trabalho, adotou-se uma identificação numérica correspondente ao seu período de uso nas escolas sendo: livro 01 - referente ao material didático usado nas escolas no período de 2002 a 2004, pois é o primeiro livro na escala de tempo decorrido do uso dos livros; quando referimo-nos ao 
livro 02, significa que é aquele utilizado nas escolas no período de 2005 a 2007, pois trata-se do segundo material didático na escala de tempo decorrido do uso dos livros, e assim respectivamente. Para uma melhor compreensão de como os livros serão nomeados, dispomos a identificação no Quadro 01:

Quadro 01: Identificação dos livros

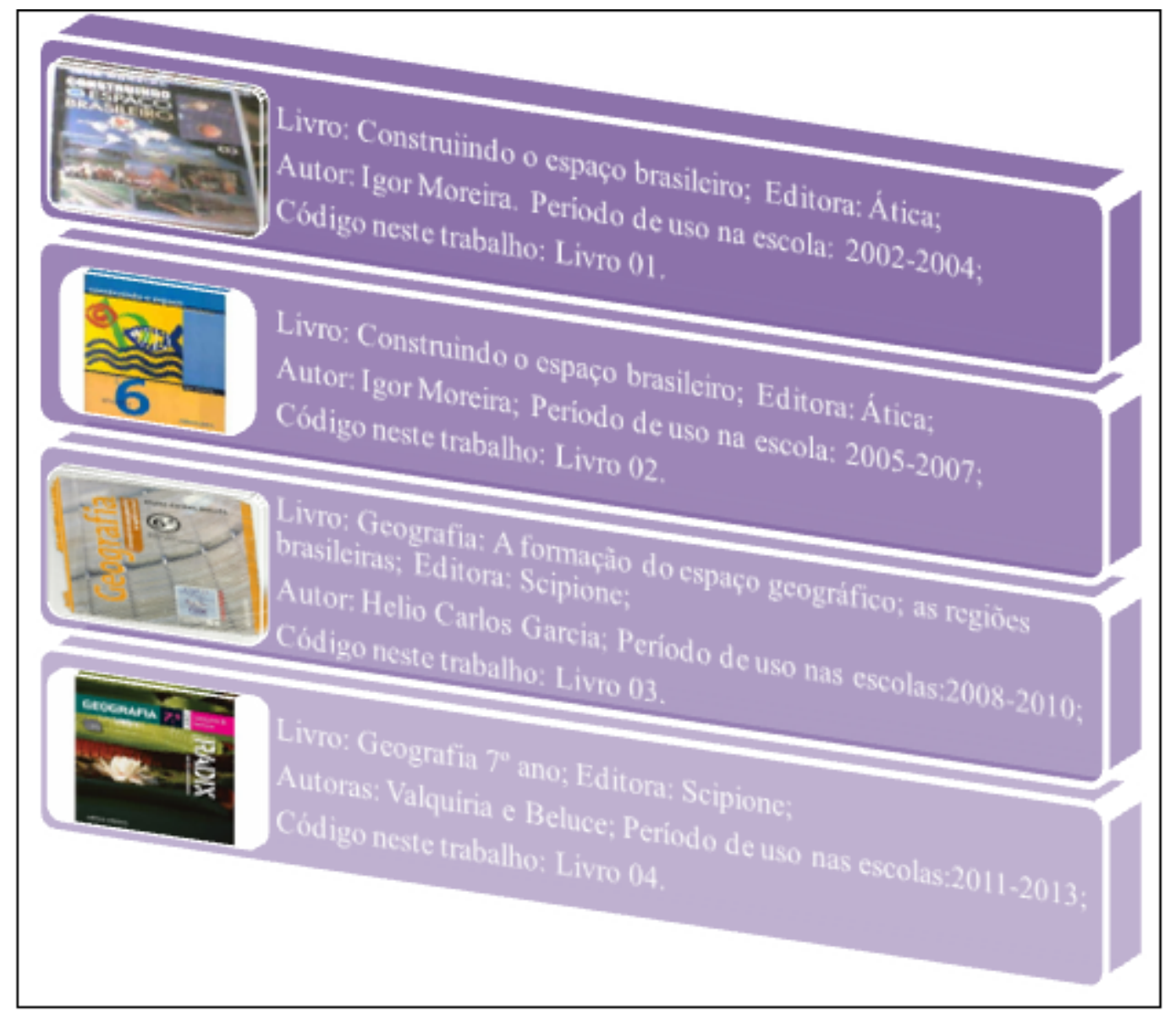

Fonte: SANTOS \& SANTOS, 2017.

A análise teve como objetivo avaliar a representação do Nordeste nos LD a partir de três categorias: como é apresentada a geografia nordestina; como são representadas as pessoas da região; e quais enredos são utilizados para construir essas representações. Salientamos que a intenção deste trabalho não é discutir qual editora, autor ou livro é melhor, mas a atuação do livro didático na propagação de dizibilidades sobre o Nordeste. O Semiárido, no entanto, apresenta-se em todos os LD como nada mais que um dos quatro tipos climáticos do Nordeste. Sendo assim, dentro da perspectiva de todos os autores dos LD analisados, as características do Semiárido Nordestino são apenas climáticas e não delineiam um espaço histórico-social.

Portanto, o trabalho tece reflexões sob a ótica do entrelaçamento dos fenômenos 
climáticos da região Nordeste e seus fenômenos histórico-sociais, além disso revela a dinâmica da negação dessas relações presentes nos LD e transmitidas nas escolas públicas do Brasil, corroborando para que se reforce o imaginário social de um Nordeste de miséria e desastres. Aqui é importante esclarecer que Nordeste diz respeito a uma localização geográfica regional, enquanto Semiárido Nordestino é o clima de determinada região (também faz-se necessário destacar que o Semiárido Brasileiro incide também no norte de Minas Gerais na região Sudeste, mas reportamo-nos apenas ao Semiárido Nordestino tendo em vista que o foco da pesquisa é o Nordeste); a seca, por sua vez, é um fenômeno climático que ocorre por fatores diversos (SENA, 2016).

Desse modo, a representatividade negativa do Nordeste nos LD opera como uma forma de cristalização e transmissão do modelo dominante de uma educação colonialista, num currículo que reforça:

\begin{abstract}
A história indígena pautada na visão do colonizador, bem assim do negro, via a negação dos valores das suas origens; da mulher, pelo machismo secular; da criança, via o adultocentrismo que permanece nos manuais pedagógicos; do homossexual, pautado numa sociedade sexualmente hipócrita, religiosamente orientada para e pela homofobia (MACEDO, 2011, p. 22).
\end{abstract}

Essa ainda é a pauta que reflete as disseminações ideológicas dos LD do Brasil, que classifica os sujeitos, desconsiderando suas diversidades (SENA, 2016) e constituindo-se em bases monorreferenciais e introduzindo suas concepções em detrimento de outras culturas e distanciando dessas a construção da identidade própria nos processos educativos.

\title{
Tessituras sobre as nordestinidades nos LD
}

É sabido e perceptível que existe, no Brasil, um cartel editorial para produção e venda de LD, conforme denunciam Munakata (1997), Martins (2006) e Sena (2016). Atualmente, o Programa Nacional do Livro Didático (PNLD) é um programa que ainda dispõe-se a estar a serviço desse cartel. Há que se reconhecer que o PNLD é, sem dúvida, um programa que galgou uma contribuição histórica no país e destaca-se mundialmente como o maior programa de distribuição gratuita de LD no mundo. Porém, mesmo com todas as suas características potenciais, esse programa ainda carece de mudanças que visem melhorar seu atendimento às escolas e não às editoras que comandam as produções de LD, o que deve ser pensado a partir de reorientações nas políticas públicas de produção, adoção e uso de LD. 
Uma forma de melhorar em tais questões deve ser a produção regional dos LD, que continue abarcando as múltiplas culturas e identidades nacionais, mas que viabilize a cada região aprofundar sobre suas potencialidades, construindo enunciados que potencializem o autorreconhecimento dos sujeitos nos LD usados para estudo, uma vez que os atuais LD distribuídos nas escolas repetem as mesmas dizibilidades de 20 ou 30 anos atrás. Exemplo disso pode ser observado na imagem encontrada em dois dos livros pesquisados (Vide Imagem 01). A mesma imagem se repete nos dois LD, reforçando que o Semiárido Nordestino é um algoz que castiga o seu próprio povo, ao passo que esse último já está acostumado a "sobreviver" a uma vida lastimável:

Imagem 01: Condições de vida do sertanejo

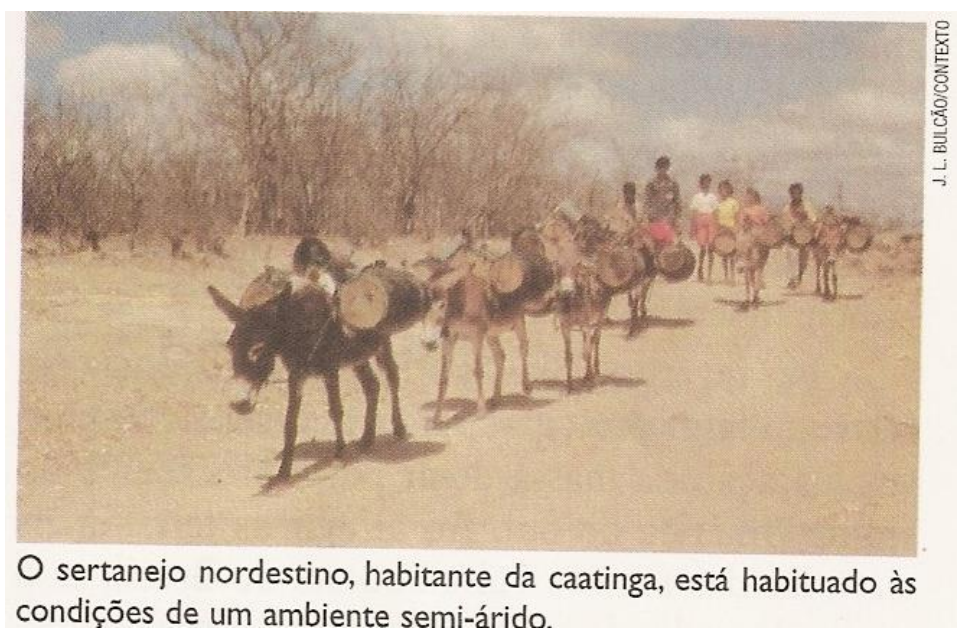

Fonte: Livros 01 (página 218) e 02 (página 242).

Por certo essa realidade mostrada na imagem foi e ainda é fato no Semiárido Nordestino. Ou seja, de fato ainda há dificuldades para a garantia da qualidade de vida de toda população sertaneja, mas é mentira admitir que as migrações, a mortalidade infantil e tantos outros fatores que estigmatizaram o Nordeste já não acontecem na mesma proporção. O que se questiona então é a atualização de informações que são fornecidas a estudantes, professores, entre outros, sem o compromisso de mostrar que os dados são móveis. Eles alteram com o passar do tempo, e talvez até seja por isso que alguns pesquisadores, como Lajolo e Zilberman (1999), sugerem que o LD pode ser enxergado como o primo pobre da literatura, uma vez que seus textos podem ser superados ou pelo tempo ou pelo avanço educacional do estudante. Um exemplo desse descompasso entre os livros, suas informações e dados atuais é a Imagem 02 disposta a seguir: 
Imagem 02: A migração extrarregional por causa da seca

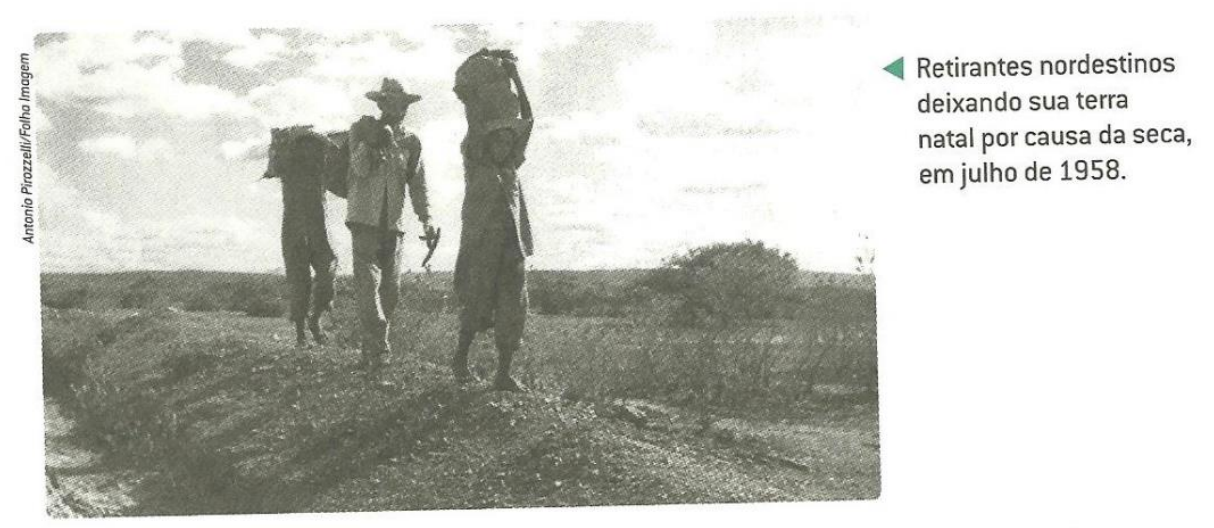

Fonte: Livro 04 (página 160).

A necessidade, portanto, é mostrar que o Semiárido Nordestino não é estagnado no tempo (como as pessoas pensam e como os livros reforçam). O texto abaixo está no livro 04 atrelado à imagem acima para descrevê-la:

\begin{abstract}
Além das mudanças ocasionadas na paisagem, a seca também provoca consequências diretas sobre a população que vive no Sertão. Durante as secas mais prolongadas, a falta de água prejudica os camponeses, sobretudo os pequenos proprietários rurais, que perdem suas lavouras de subsistência e os pequenos rebanhos. Sem condições de sobreviver com o sustento da terra, muitas famílias abandonam o campo e migram para outras áreas fugindo das secas (LIVRO 04, p. 160).
\end{abstract}

Através dessa imagem e do texto aliado a ela, o que se pode pensar sobre essa realidade é que isso é fato não só do passado, mas ainda é algo presente e na mesma intensidade, pois o texto que antecede a imagem reforça o discurso da migração durante a seca no tempo presente. Ou seja, são conceitos disseminados, ao longo do tempo pela mídia, pelos LD e reforçados pela escola como verdades imutáveis. Nessa perspectiva, o conceito de Semiárido Nordestino não pode, pois, ser tomado apenas como nome que nomeia uma realidade, que a descreve com tais e tais características territoriais, climáticas, culturais, etc.

No entanto, o Nordeste apresentado nos LD analisados na pesquisa ainda não possibilita um destaque que permita aos educandos se afirmarem positivamente como sujeitos desse espaço geográfico e social. Começando na ordem de estudos sobre as regiões brasileiras, a região Nordeste, nos livros 01 e 02 , é a penúltima apresentada. Já, nos livros 03 e 04, o Nordeste é a segunda região a ser estudada e isso deve ser 
questionado no nível das prioridades dos autores, pois num posicionamento geográfico do país, as regiões deveriam ser classificadas não por opiniões pessoais, mas pela sua localização socioespacial, de forma justa, para não supervalorizar algumas regiões em detrimento de outras.

Dessa forma, deve-se considerar a abordagem de cada região por sua localização no mapa brasileiro. No entanto, o desprestígio social dado ao Nordeste nas páginas dos LD estudados se revela através de comparações nos textos e imagens que buscam sempre comparar fatores sociais, políticos, históricos e ambientais. Nos contextos e prescrições apresentados nos LD, o Nordeste se recorta e cola nos aspectos da vegetação, de suas questões climáticas e condições de produção.

A vegetação nordestina é mista, pois comporta Caatinga, Cerrado, Floresta Equatorial, Floresta Tropical, Mata de Cocais e a Vegetação Litorânea. Formada após o fenecimento do último período glacial, através da adaptação de sua fauna e flora, a Caatinga $^{3}$ brota na natureza como o único bioma exclusivamente brasileiro. Segundo Malvezzi (2009),

Bioma é um conjunto de vida (vegetal e animal) constituído pelo agrupamento de tipos de vegetação contíguos e identificáveis em escala regional, com condições geoclimáticas similares e história compartilhada de mudanças, o que resulta em uma diversidade biológica própria (p.51).

Nesse sentido, admitir a Caatinga enquanto bioma é reconhecer sua identidade, diversidades e potencialidades no tocante ao que o bioma de fato comporta. $\mathrm{O}$ espaço territorial da Caatinga é de $1.037 .000 \mathrm{~km}^{2}$, uma expansão que corresponde a $12 \%$ do território brasileiro e $70 \%$ do território nordestino e abriga $63 \%$ da população nordestina, correspondente a $12 \%$ da população brasileira. Nos LD analisados, o Nordeste é tratado e retratado, no sentido imagético da palavra, como um ambiente difícil, pobre, doente e sem condições viáveis de uma vida digna (LIVRO 01, p. 242). Esse desprestígio se desnuda quando o único bioma exclusivamente brasileiro não é reconhecido como tal. $\mathrm{Na}$ verdade, para os autores dos quatros livros analisados, segundo os achados da pesquisa, a Caatinga é feia, é seca, é inviável e cada autor demonstra essa indiferença ao referido bioma de formas diferentes. Tentando referenciar o processo de transformação da Caatinga, o autor do livro 01, na página 220

1 Numa das linguagens das diversas etnias indígenas brasileiras o nome "caa" significa mata e "tinga" significa branca, devido ao período de hibernação da vegetação onde a mata aparece com um aspecto esbranquiçado ou acinzentado. 
diz: “(...) Um pouco de chuva e, como por um milagre, a mata até então cinzenta, feia e ressequida se cobre de brotos e folhas verdes".

É nesse momento que vemos que o modelo de beleza e a concepção de feiura não têm suas raízes em outro fator senão a colonialidade, pois, especificamente nesse caso, para os primeiros relatores do espaço geográfico brasileiro, a vegetação como um todo precisava estar representada na roupagem de uma grande floresta. Para o autor dos livros 01 e 02 e para muitos pode ser feio e parecer morto, para tantos outros pode ser a maior demonstração de inteligência da natureza. De acordo com Carvalho e Schistek (2011), os livros continuam chegando à escola com imagens tantas que chegam a assustar a quem vê:

\begin{abstract}
Enquanto isso, os LD continuam chegando às escolas do semiárido, apresentando em seus títulos, fotos e textos uma "Caatinga morta". Isso nos assusta, pois os sertanejos sabem que nos intervalos entre dois períodos de chuva, chega-se a ser de oito meses, e a Caatinga entra em hibernação, mantendo o metabolismo em nível mais baixo possível. Mas, lá está a vida latente, cheia de força embaixo da casca das árvores, a seiva está sob pressão, cheia de nutrientes. E, muito antes da primeira chuva, que ocorre em fins de novembro, início de dezembro, já aparecem as primeiras flores (p. 50).
\end{abstract}

Hoje, ainda se pregam conceitos de que a Caatinga é seca e ríspida e por isso renega-se o único bioma que de fato só existe no Brasil. Contudo, esse tipo de vegetação, ao mesmo tempo, desperta curiosos do exterior, apesar de ser antipatizada por seus compatriotas. Essa antipatia fica clara nos LD, quando frequentemente comparam a Caatinga a frondosas e enormes árvores, ou ainda quando é claramente considerada feia no real sentido da palavra no seu período de descanso como vimos anteriormente. $\mathrm{O}$ fato é que, de acordo com a análise dos livros, o bioma Caatinga, um dos nossos patrimônios naturais é negado, é estereotipado e sempre associado a opiniões que não despertam o sentimento de pertencimento ou sequer uma relação compatrícia.

Diante disso nenhum cidadão que estude sobre a Caatinga como essa está posta nos livros vai querer absorver esse ambiente como algo seu. Ou seja, como gostar do feio, seco, morto e pobre? Pois é dessa maneira que a Caatinga e o sertanejo são retratados nos livros pesquisados, além de serem associados à imagem de um clima propício à miséria, causticante e flagelador. Por certo viver no Semiárido Nordestino, bem como em qualquer outro lugar do mundo, tem suas possibilidades e desafios, mas isso não é só questão climática, é um conjunto de fatores, inclusive humanos, mas, principalmente, políticos que movem a ausência de políticas públicas no Semiárido Nordestino. 
Leia-se ainda que a imagem principal que reporta a ideia dentre as características que se destacam sobre esse espaço é a imagem do lugar atrasado, do homem e da mulher com a família cheia de filhos doentes, descalçados, barrigudos, etc. Os LD ainda buscam reforçar que as condições favoráveis a uma boa produção estão no litoral, que as possibilidades estão no litoral e que a umidade e fertilidade de solos estão no litoral:

O Nordeste apresenta um quadro natural típico de semiaridez, com clima quente e seco, predomínio de vegetação de caatinga e a presença de rios temporários. É bom lembrar que elas estão presentes apenas no Sertão. O litoral, ao contrário, caracteriza-se por apresentar grande umidade e solos férteis (LIVRO 01, p. 59).

Obviamente, é inconveniente negar a realidade e os fatores causais tais como hídricos, geográficos e políticos. Todavia, sabe-se que existe um estereótipo que configura a imagem do indivíduo sertanejo à caricatura do homem pobre, analfabeto, desolado, doente, obrigado a deixar sua terra em busca de emprego, e alimento.

\footnotetext{
Ou seja, é uma região que é vista por uma caricatura que criaram da gente. A imprensa nacional e os que escreveram sobre esta região, tendo como parâmetros apenas uma época do ano, ou apenas um ângulo da região, não perceberam a sua complexidade do Semiárido Brasileiro. Os LD que circulam na nossa região reforçam essa imagem negativa da região, do sujeito que vive no Semiárido, que é visto como 'matuto' ou como um 'sujeito sem saber' (REIS, 2010, p. 112).
}

Além dessas características atreladas ao Semiárido Nordestino pela imprensa, nas expressões artísticas e literárias existem ainda os discursos construídos estrategicamente ao longo da história, para se criar uma política com vistas à disseminação de uma imagem negativa sobre o "sertão", de maneira que o associem à pobreza, miséria e fome, com a estratégia única de captação de recursos junto ao governo federal. Assim, as políticas públicas voltadas para a região Nordeste eram ainda pautadas sob a ótica de que os fatores climáticos do Semiárido Nordestino exigiam medidas de combate propondo que a miséria, a fome e outros fatores sociais eram oriundos da seca, a qual necessitava de recursos específicos para ser combatida, no entanto, tais recursos beneficiaram primordialmente os grandes empresários e donos de terras da região, dissociando as causas naturais de efeitos políticos.

A presença do Semiárido Nordestino nos LD ainda é rasa. Claro que os dados positivos são praticamente negligenciados como as potencialidades territoriais, o conhecimento historicamente produzido e os avanços das tecnologias de convivência com o Semiárido, enquanto dados negativamente relacionados às condições de vida são mostrados majoritariamente como retrato da região. Os aspectos geográficos e os de 
interesse do setor industrial e a fruticultura irrigada para o agronegócio aparecem como o único meio viável de desenvolvimento para o "sertão" em todos os livros analisados.

O elemento gráfico, construído a partir desta pesquisa, mostra os conceitos mais relevantes, na ótica dos autores, e os espaços que esses ocupam nos livros. Na verdade, cada livro traz uma ordem de apresentação. Com exceção dos livros 01 e 02 que, por serem de mesma autoria, apenas retiram ou acrescentam algumas palavras, mantendo basicamente idêntica a estrutura se compararmos um ao outro. No livro 04 há um fator mais discutido ao se apresentar a região Nordeste: a seca.

A seca no livro 04 é o enredo central de um material didático marcado por imagens e discursos preconceituosos, visto que, durante toda a unidade de estudo da região Nordeste, as temáticas centrais voltam-se para a seca como a causadora das mazelas dessa região, finalizando sutilmente com o discurso de que os únicos espaços viáveis do Nordeste se encontram na faixa litorânea. Esse quadro pode ser considerado como uma das explicações que justificam o fato de habitantes do Semiárido Nordestino não terem, na escola, um suporte na produção de respostas pertinentes para os vários desafios que têm que enfrentar diariamente. E, ainda, acabam incorporando uma cisma de seu próprio meio, veiculado como hostil, onde a vida é inviável - o que, potencialmente naturaliza a migração.

E é nesse ponto que toca a criação de livros que possam atuar como novos instrumentos pedagógicos que tratem de conhecimentos específicos desse espaço Semiárido Nordestino, possibilitando a valorização da cultura e reconhecimento da gente desse lugar, para desvelar e desmistificar as teorias e histórias depreciativas dessa realidade tão cheia de belezas. Mas como se reconhecer numa realidade posta como distante de tudo? Os livros não trazem um aporte teórico que possa subsidiar esse prestígio, pelo contrário, representam os problemas nacionais com fotos de algumas realidades nordestinas, supervalorizando-as e não citando os problemas como um todo.

Por exemplo, ao se discutir o trabalho infantil no país o autor do livro $02 \mathrm{o}$ representa com uma foto de uma criança vendendo algodão doce em Salvador/BA e outra foto de um menino negro trabalhando na colheita de sisal em Retirolândia/BA. No mesmo texto, ao abordar a mortalidade infantil e as más condições de vida das crianças no país, há uma imagem com duas partes, uma superior e outra inferior. A imagem superior apresenta três crianças brincando num lixão em Salvador/BA, e em contraste a isso a parte inferior mostra uma criança recebendo vacinação em São Paulo. Todas as fotos pertencem a um mesmo grupo de textos e conteúdos do livro 02. 
O livro 02 sempre exemplifica conflitos brasileiros com fotos de realidades nordestinas, mostrando apenas imagens de crianças nordestinas e negras nos prejuízos e pessoas brancas num patamar de benefício em relação às outras, sendo que a criança da parte inferior da imagem não representa apenas que a criança precisa receber a vacina. Ela representa o desenvolvimento da saúde, aquela que possui condições favoráveis à vida, cuja mãe não foi buscar uma lata d'água na cabeça, porque o pai trabalha no setor industrial, cujo salário que recebe consegue manter uma família. Ou talvez não, a brancura dessas criaturas esteja posta para representar apenas a vontade de se apresentarem situações favoráveis ao Sudeste, como se não fosse possível colocar uma realidade nordestina favorável.

A pobreza, a miséria, as "condições desfavoráveis à vida cujas pessoas são impedidas de exercer a própria cidadania” (LIVRO 01, p. 242) são representadas pelas imagens do Nordeste, no entanto, para representar o desenvolvimento, o acesso às políticas de direitos representada pela vacinação, surge a criança de São Paulo. O fato é que o povo nordestino é sempre o elenco protagonista nos enredos inferiores nesses LD, por outro lado a população do Sudeste é sempre colocada num patamar elevado com relação à população do Nordeste. Albuquerque Júnior (1999) explica a historicidade dessa disputa do Norte ${ }^{4}$ versus Sul desde o final do século XIX, argumentando que o Sul seria “(...) o fundamento da nação, em detrimento daquelas áreas onde dominavam as camadas plebeias, mestiças, profusa mistura de sangues bárbaros, inferiores psicologicamente, ou desorganizadas em sua inferioridade" (p. 57). Para esse autor, havia uma disputa de um regionalismo naturalista naquela época, o que disseminou uma visibilidade mais aguçada das condições naturais do meio, proporcionando assim que as características mais visíveis do Semiárido Nordestino servissem como estereótipo para argumentar a incapacidade humana dessa gente.

A crença nesse discurso levou o país a criar uma imagem de que o Norte do país estaria condenado, pelo próprio clima, a não acompanhar o desenvolvimento do Sul e até mesmo regredir. Esse discurso vai gerar uma série de ideias sobre o enxerto de dinheiro nas regiões pelo estado, unificando interesses dos poderosos para angariar fundos para seus negócios. Gilberto Freyre, segundo Albuquerque Júnior (1999), nomeia essa prática como a "elite regional" que perdura durante muito tempo com os

2 Na perspectiva de Albuquerque (1999), o Norte até o fim da década de 1930 contemplava o que hoje é o Nordeste e Norte do país. O Sul abrangia desde a Bahia até o Rio Grande do Sul. Desse modo a concepção de divisão regional do país, até então, era somente Norte e Sul. 
argumentos de que os estados do Norte estão sujeitos a um fenômeno climático arrasador e, por isso, a região é marginalizada, flagelada e sofredora, sendo abandonada pelos poderes públicos.

Os traçados históricos do Nordeste se intensificam, quando discorre-se sobre a área sertaneja. Na verdade, o que configura todo esse processo histórico de formação de conceitos sobre o Nordeste são as características da gente do Sertão, do povo do Semiárido Nordestino que são lembradas, pois as condições históricas se entrelaçam aos fenômenos climáticos dessa região. Nos achados da pesquisa, as características do povo são sempre as de pessoas não alfabetizadas, pobres e sem condições de uma vida digna. O Quadro 02 abaixo, elaborado a partir de trechos de textos dos LD, pode dar maior visibilidade às falas dos autores na ótica dos traços do povo do Semiárido Nordestino presente nos LD.

Quadro 02: Dizibilidades sobre o Nordeste

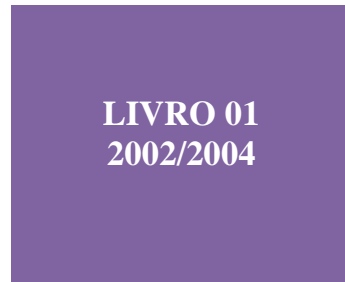

"P. 242: Observa-se que a maior parte dos habitantes vive na pobreza, morando em condições precárias, sem água encanada ou rede de esgotos." "P. 242: O baixo nível educacional dificulta a qualificação dos trabalhadores e diminui suas oportunidades de alcançar condições adequadas de sobrevivência e de exercer a própria cidadania."

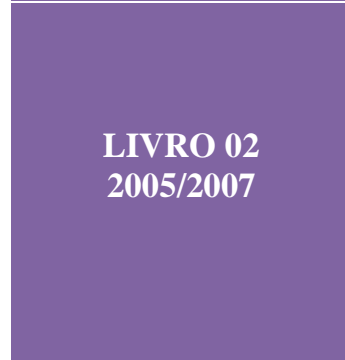

"P. 259: Observa-se que a maior parte dos habitantes vive na pobreza, morando em condições precárias, sem água encanada ou rede de esgotos. $\mathrm{O}$ grande número de analfabetos é uma forte limitação para o desenvolvimento econômico, político e social da região."

"P. 259: O baixo nível educacional dificulta a qualificação dos trabalhadores e diminui suas oportunidades de alcançar condições adequadas de sobrevivência e de exercer a própria cidadania."

LIVRO 03

$2008 / 2010$

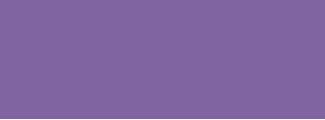

LIVRO 04

2011/2013
"P. 148: Quanto ao movimento extrarregional, notamos que, nas últimas décadas, o Nordeste transformou-se em uma área repulsora de população, sobretudo pelas difíceis condições de existência que sua população enfrenta."

"P. 148: Na região Nordeste, apenas $65,2 \%$ da população vive em cidades."

"P. 160: Mais recentemente, no entanto, grande parte dos trabalhadores que deixam o Sertão tem migrado para as grandes cidades da própria região Nordeste, como Salvador, Recife e Fortaleza, entre outras cidades que estão passando por um período de crescimento econômico. Essa migração tem causado sérios problemas, como inchaço populacional e aumento da favelização."

Fonte: SANTOS \& SANTOS, 2017.

A população nordestina é referenciada como a mais pobre, analfabeta, sem 
expectativa de vida, sem acesso às condições legais de saúde e trabalho digno. Segundo o autor do livro 03, na página 148: "Na região Nordeste, apenas $65,2 \%$ da população vive em cidades". Ainda não se tem muita clareza sobre esse fenômeno de fixação da população caatingueira no campo. A fala do autor do livro 01 e 02, nas páginas 242 e 259 , respectivamente, mostra uma concepção fundamentada em dados de uma realidade questionável, pois, quando afirma que “(...) a maior parte dos habitantes vive na pobreza, morando em condições precárias, sem água encanada ou rede de esgotos”, é importante e mais do que necessário se questionar sobre essa afirmação e inquirir sua veracidade.

É fato que há grandes discrepâncias socioeconômicas na região Nordeste, no entanto também sabemos que até mesmo os meios de pesquisa que calculam esses dados precisam ser avaliados como reais e quais seus interesses, pois conhecemos que historicamente a região Nordeste foi e é vítima de um discurso granjeador de fundos para o enriquecimento dos ricos e a permanência dos pobres e miseráveis para que constantemente esses fundos permaneçam como uma poupança.

Estudiosos buscam conhecer quais são os fatores que prendem tão grande número de pessoas num lugar considerado como inviável, inóspito. $\mathrm{O}$ fato é que o povo sertanejo já estabeleceu uma relação histórica e cultural com esse meio. Malvezzi (2009) vai explicar que, além disso, o povo estabeleceu também uma relação afetiva com o meio:

\footnotetext{
O povo caatingueiro é apaixonado pela Caatinga e, ainda que precariamente, aprendeu a viver em seu ambiente. A criação de pequenos animais, a apicultura, a água colhida em reservatórios escavados no chão e outras soluções possibilitam que o povo nasça, cresça e se reproduza, embora migrem intensamente, para ir e para voltar (p.57).
}

A fala do autor do livro 02, p. 259, afirmando que “(...) o grande número de analfabetos é uma forte limitação para o desenvolvimento econômico, político e social da região", é uma afirmativa construída através de um processo histórico colonialista pautado também na mesma perspectiva de usar o enérgico discurso da indústria da seca, “(...) a poderosa arma que tinham em mãos, para reclamar tratamento igual dado ao Sul” (ALBUQUERQUE, 1999, p. 70). Nos LD analisados, o Nordeste aparece como a região conflituosa e que serve como banco de dados para representações dos problemas do país. No entanto, para abordar como se deu a alavanca de desenvolvimento do país, o Sul e o Sudeste são exaltados como se não tivessem qualquer tipo de conflito social.

O livro, no entanto, traz algumas imagens em seu contexto para abordar os 
problemas sociais brasileiros, o crítico disso é que os textos dos problemas apresentados são sempre ilustrados por imagens de situações nordestinas. O povo nordestino também se configura nos livros como o povo flagelado causador das epidemias das outras regiões brasileiras e das cidades litorâneas nordestinas. O autor do livro 04, na página 160, afirma que:

\begin{abstract}
Mais recentemente, no entanto, grande parte dos trabalhadores que deixam o Sertão tem migrado para as grandes cidades da própria região Nordeste, como Salvador, Recife e Fortaleza, entre outras cidades que estão passando por um período de crescimento econômico. Essa migração tem causado sérios problemas, como inchaço populacional e aumento da favelização.
\end{abstract}

Atrelado a esse texto, o autor revela uma imagem onde a população sertaneja, mais uma vez, é caricaturada como a grande criadora das deficiências do país. É esse retrato que está posto nos $\mathrm{LD}$ e são essas as informações (re)produzidas a partir do ponto de vista do Sudeste que circulam nas escolas e vêm para a nossa região. As editoras e autores podem até ter considerado o modismo de uma falsa contextualização e tentado colocar uma realidade plástica nos livros para tentar representar um pouco do povo sertanejo e seu percurso na sociedade.

Analisando o que se diz no texto, entende-se que é a população sertaneja a causadora de mazelas de outrem. Porém, engana-se quem pensa que contextualizar é apenas representar imageticamente e falar sobre uma determinada realidade, a contextualização já pressupõe dialogar com determinada realidade onde o sujeito que lê também se reconhece como autor daquele texto ou imagem. Por exemplo, a leitura do texto acima citado (livro 04, p. 160) implica afirmar que alguém de qualquer outra região brasileira lê sobre o "sertão" e seu povo marginal que lota as cidades litorâneas desenvolvidas ocasionando as favelas miseráveis e problemáticas. É contra o discurso do longe, do outro e a favor de uma prática que dê visibilidade ao aqui. É fato que as migrações intrarregionais acontecem em uma proporção preocupante e ainda precisamos de políticas públicas que possam garantir a permanência das pessoas em sua terra.

Mas o que se precisa avaliar é que "(...) a voz de quem fala é de alguém que está 'fora', falando de algo que acontece lá com os nordestinos coitados, caracterizando-se num processo de colonização interna. E esses livros chegam às escolas do Sertão" (LINS, 2007, p. 72) e os alunos que estudam com esses livros vivem numa realidade de migração junto a seus pais e mães em busca de empregos, tendo em vista que o pedaço de terra que outrora tinham já não lhes pertence mais. Essa (a terra) fora comprada por 
um empresário do agronegócio em nome de um falso desenvolvimento, ou até mesmo fora abandonada pelo sertanejo que ao longo de muitos anos fez o manejo incorreto dos recursos naturais, pelo desconhecimento das potencialidades do Semiárido aliada a uma falsa informação de que sua terra é pobre. Silva (2010) explica os errôneos conceitos sobre a região:

\begin{abstract}
Enquanto as interpretações dominantes colocam a culpa do atraso na natureza, na escassez hídrica e na baixa capacidade produtiva dos solos, há uma nova interpretação exatamente ao contrário: foi a falta de uma adequada compreensão sobre os limites e potencialidades dessa realidade que conduziu a introdução de atividades econômicas não apropriadas que terminaram por agravar ainda mais os problemas ambientais, quebrando o equilíbrio ecológico existente e empobrecendo mais ainda as famílias sertanejas (p.71).
\end{abstract}

A perspectiva da convivência apoia a reconstrução do discurso sobre a terra. $\mathrm{O}$ aluno que lê esse texto é o mesmo que às vistas do autor do livro 04, p. 160 , “(...) tem causado sérios problemas, como inchaço populacional e aumento da favelização" e aguarda sofregamente políticas públicas que viabilizem o acesso à terra e condições viáveis da permanência e do trabalho na mesma. É bem verdade que a população sertaneja encontra difíceis condições de permanência na terra, mas é nesse ponto que surge a necessidade de uma adaptação da economia à realidade do Semiárido, que possam promover a justiça social, visando o acesso a recursos naturais do Semiárido Nordestino “(...) principalmente à terra e à água, na adoção de iniciativas capazes de contribuir para a transformação e fortalecimento da economia do Semiárido" (SILVA, 2010, p. 71). A aplicação de políticas públicas viáveis para o Semiárido Nordestino possibilitará esse acesso e permanência do povo sertanejo em seu chão, diminuindo significativamente as migrações.

É nesse ponto que se deve questionar o caráter de autoridade do LD, não só para os professores ditos fiéis ao livro, mas o exercício docente como um todo. Souza (2011) explica que o livro já carrega uma “(...) verdade sacramentada a ser transmitida e compartilhada. Verdade já dada que o professor, legitimado e institucionalmente autorizado a manejar o LD, deve apenas reproduzir, cabendo ao aluno assimilá-la" (p. 27). A partir disso, deve-se questionar as verdades até então inquestionadas, as autoridades reforçadas pelo autor de um livro sujeito aos interesses de uma editora, que, por sua vez, está sujeita aos interesses ideológicos do estado. Tais razões ideológicas estão ligadas à questão do modo da informação a partir da seleção dos assuntos a serem veiculados na escola; é relativo ao que pode e deve ser dito, ao que pode ser escrito e, posteriormente, veiculado na sociedade/escola. 


\section{Considerações Finais}

O LD é fruto de um processo histórico de políticas oficiais de educação e é subjetivado por uma série de conceitos e fatos que necessita considerar. Ainda que adapte e readapte ideias concebidas para ser aceito num universo institucionalizado e institucionalizante como é a escola, o LD está sujeito a alguns moldes de conduta necessários ao seu avanço, de modo que procure afastar-se de retrocessos.

Os LD analisados também estão carregados de conceitos e ideias concebidas para agradar a um público. De maneira intencional, trazem significados importantes como a informação, o conhecimento e realidades históricas do mundo construídas ao longo do tempo que num só material conseguem ser reunidas. Além disso, o LD proporciona ao professor o contato com textos diversos e o acesso a novas atividades que viabilizam a sua prática pedagógica. A dinâmica com o LD deve, a partir do professor, acontecer de maneira que o aluno torne-se um sujeito leitor. Desse modo, pensar o LD na ótica da pesquisa requer conversar sobre os conceitos trazidos pelos livros pesquisados, além dos conceitos aqui já discorridos.

Também deve-se refletir que os LD necessitam propiciar a importância da convivência - não só com o Semiárido, mas com a realidade do aluno leitor - respaldar o diálogo, possibilitando a alunos e professores o acesso a subsídios adequados e necessários ao crescimento individual, intelectivo e igualitário dos atores abarcados no processo educativo. Evitando, desse modo, propagar conceitos e opiniões pessoais, préconceitos ou estereótipos. Mas o que se vê na pesquisa é uma contínua impregnação, contida nos LD de conceitos estereotipados ao longo do tempo, para a região Nordeste, como uma ideologia que, gradativamente, atua como uma manipulação das consciências dos indivíduos sobreposta por uma classe dominante racista, sexista e eurocentrada.

\section{Referências}

ALBUQUERQUE Jr., Durval Muniz de. A invenção do Nordeste e outras artes. São Paulo: Cortez. 1999.

CARVALHO, L. D. \& SCHISTEK, H. A formação histórico-geográfica do Semiárido Brasileiro. In: RESAB. Educação e Convivência com o Semiárido: Reflexões por dentro da UNEB. Juazeiro: Selo Editorial RESAB, 2011.

GARCÍA, H. C. A formação do espaço geográfico: as regiões brasileiras. São Paulo: Scipione, 2007. 
LAJOLO, M.; ZILBERMAN, R. A formação da leitura no Brasil. São Paulo: Ática, 1999.

LINS, Cláudia e ANTUNES, Maisa. O tempo está bonito pra chover: Experiência da produção de materiais didáticos contextualizados no Semi-Árido Brasileiro. In: RESAB. Currículo, Contextualização e Complexidade: elementos para se pensar a escola no Semi-Árido. Juazeiro/BA: Selo Editorial RESAB, 2007.

MACEDO, R. S. Outras luzes: um rigor intercrítico para uma etnopesquisa política. In: MACEDO, R. S. (Org.). Um rigor outro: sobre a qualidade na pesquisa qualitativa, educação e ciências antropossociais. Salvador: EDUFBA, 2011.

MALVEZZI, Roberto. Semi-Árido - uma visão holística. Brasília: Confea, 2007.

MARTINS, J. da S. Anotações sobre a interação em rede. In: RESAB. Educação para a Convivência com o Semiárido: Reflexões teórico-práticas. $2^{a}$ ed. Juazeiro/BA: Secretaria Executiva da Rede de Educação do Semiárido Brasileiro, Selo Editorial RESAB, 2006.

MOREIRA, I. Construindo o espaço brasileiro. São Paulo: Ática., 2001.

MOREIRA, I. Construindo o espaço brasileiro. São Paulo: Ática., 2004.

MUNAKATA, K. Produzindo Livros Didáticos e Paradidáticos. Tese (Doutorado em Educação) - Programa de Pós-Graduação em História e Filosofia da Educação, Pontifícia Universidade Católica de São Paulo, São Paulo, 1997.

PIRES, V. \& BELLUCCI, B. Projeto Radix: raiz do conhecimento - Geografia - $7^{\circ}$

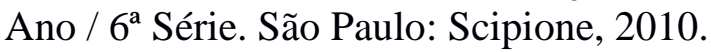

REIS, E. dos S. Educação para a Convivência com o Semiárido: Desafios e possibilidades. In:

INSA. Semiárido Piauiense: Educação e Contexto. INSA. Campina Grande: 2010.

SENA, R. R. O. Uso-teste dos livros didáticos “Conhecendo o Semiárido 1 e 2" no município de Juazeiro/BA: implicações na prática pedagógica. Dissertação apresentada ao Programa de Pós Graduação Mestrado em Educação Cultura e Territórios Semiáridos Universidade do estado da Bahia. Juazeiro/BA: 2016.

SILVA, R. M. da. Concepções de desenvolvimento: convivência e sustentabilidade no Semiárido brasileiro. In: INSA. Semiárido Piauiense: Educação e Contexto. INSA. Campina Grande: 2010.

SOUZA, Deusa Maria de. Autoridade, Autoria e Livro didático. In: CORACINI, Maria José (Org.). Interpretação, autoria e legitimação do livro didático. São Paulo: Pontes, 2011. 